\title{
Lobular carcinoma in situ and invasive lobular breast cancer are characterized by enhanced expression of transcription factor AP- $2 \beta$
}

\author{
Mieke Raap', Malte Gronewold', Henriette Christgen', Silke Glage², Mohammad Bentires-Alj³, Shany Koren³, \\ Patrick W Derksen ${ }^{4}$, Mirjam Boelens ${ }^{5}$, Jos Jonkers ${ }^{5}$, Ulrich Lehmann ${ }^{1}$, Friedrich Feuerhake ${ }^{1}$, Elna Kuehnle ${ }^{6}$, Oleg Gluz ${ }^{7,8}$, \\ Ronald Kates ${ }^{7}$, Ulrike Nitz ${ }^{7,8}$, Nadia Harbeck ${ }^{7,9}$, Hans H Kreipe ${ }^{1}$ and Matthias Christgen ${ }^{1}$
}

Transcription factor AP-2 $\beta$ (TFAP2B) regulates embryonic organ development and is overexpressed in alveolar rhabdomyosarcoma, a rare childhood malignancy. Gene expression profiling has implicated AP- $2 \beta$ in breast cancer (BC). This study characterizes AP- $2 \beta$ expression in the mammary gland and in BC. AP- $2 \beta$ protein expression was assessed in the normal mammary gland epithelium, in various reactive, metaplastic and pre-invasive neoplastic lesions and in two clinical BC cohorts comprising $>2000$ patients. BCs from various genetically engineered mouse (GEM) models were also evaluated. Human BC cell lines served as functional models to study siRNA-mediated inhibition of AP-2 $\beta$. The normal mammary gland epithelium showed scattered AP- $2 \beta$-positive cells in the luminal cell layer. Various reactive and preinvasive neoplastic lesions, including apocrine metaplasia, usual ductal hyperplasia and lobular carcinoma in situ (LCIS) showed enhanced AP-2 $\beta$ expression. Cases of ductal carcinoma in situ (DCIS) were more often AP-2 $\beta$-negative $(P<0.001)$. In invasive $\mathrm{BC}$ cohorts, $\mathrm{AP}-2 \beta$-positivity was associated with the lobular $\mathrm{BC}$ subtype $(P<0.001)$, loss of E-cadherin $(P<0.001)$, a positive estrogen receptor $(\mathrm{ER})$ status $(P<0.001)$, low Ki67 $(P<0.001)$, low/intermediate Oncotype DX recurrence scores $(P<0.001)$, and prolonged event-free survival $(P=0.003)$. BCs from GEM models were all AP-2 $\beta$-negative. In human $\mathrm{BC}$ cell lines, AP- $2 \beta$ expression was independent from ER-signaling. SiRNA-mediated inhibition of AP- $2 \beta$ diminished proliferation of lobular BC cell lines in vitro. In summary, AP-2 $\beta$ is a new mammary epithelial differentiation marker. Its expression is preferentially retained and enhanced in LCIS and invasive lobular BC and has prognostic implications. Our findings indicate that AP- $2 \beta$ controls tumor cell proliferation in this slow-growing BC subtype. Laboratory Investigation (2018) 98, 117-129; doi:10.1038/labinvest.2017.106; published online 16 October 2017

The activator protein-2 (AP-2) family of transcription factors comprises five members (AP- $2 \alpha,-2 \beta,-2 \gamma,-2 \delta,-2 \varepsilon)$, which are encoded by separate genes (TFAP2A, TFAP2B, TFAP2C, TFAP2D, TFAP2E). ${ }^{1}$ AP-2 proteins bind GC-rich DNA sequences and mediate both activating and repressive stimuli. AP-2 proteins function in a cell type-specific manner and regulate embryonic organ development, differentiation and tissue homeostasis. During embryogenesis, AP- $2 \alpha$, AP- $2 \beta$, and $\mathrm{AP}-2 \gamma$ display partially overlapping expression patterns in the nervous system, the facial mesenchyme, the limbs and various epithelia. ${ }^{1-4} \mathrm{AP}-2 \delta$ and $\mathrm{AP}-2 \varepsilon$ are restricted to the central nervous system. ${ }^{5}$ AP-2 knock-out studies in mice have documented lethal phenotypes with different developmental abnormalities related to premature differentiation or unbalanced apoptosis. ${ }^{1}$

The human TFAP2B gene is primarily known for its association with the Char syndrome, an autosomal dominant disorder characterized by patent ductus arteriosus, facial dysmorphism and anatomical abnormalities of the fifth digit. ${ }^{6}$ Genetic analyses in Char syndrome siblings have revealed TFAP2B missense mutations. ${ }^{6}$ A common TFAP2B polymorphism (rs987237) is associated with obesity. ${ }^{7}$ More recently, TFAP2B has been implicated in neoplastic diseases. ${ }^{8-12}$ TFAP2B is overexpressed in alveolar

\footnotetext{
${ }^{1}$ Institute of Pathology, Hannover Medical School, Hannover, Germany; ${ }^{2}$ Institute of Laboratory Animal Science, Hannover Medical School, Hannover, Germany; ${ }^{3}$ Department of Biomedicine, University of Basel, University Hospital Basel, Basel, Switzerland; ${ }^{4}$ Department of Pathology, University Medical Center Utrecht, Utrecht, The Netherlands; ${ }^{5}$ Division of Molecular Pathology, the Netherlands Cancer Institute, Amsterdam, The Netherlands; ${ }^{6}$ Department of Gynecology and Obstetrics, Hannover Medical School, Hannover, Germany; ${ }^{7}$ West German Study Group, Moenchengladbach, Germany; ${ }^{8}$ Breast Center Niederrhein, Evangelic Bethesda Hospital,

Moenchengladbach, Germany and ${ }^{9}$ Breast Center, Department of Obstetrics and Gynecology, University of Munich, Munich, Germany

Correspondence: PD Dr M Christgen, PhD, Institute of Pathology Hannover Medical School, Carl-Neuberg-Str. 1, 30625 Hannover, Germany.

E-mail: Christgen.Matthias@MH-Hannover.de

Received 19 April 2017; accepted 14 August 2017
} 
rhabdomyosarcoma (aRMS), a rare childhood malignancy. ${ }^{8}$ Approximately $80 \%$ of aRMSs harbor translocations $\mathrm{t}(2 ; 13)$ or $\mathrm{t}(1 ; 13)$, which juxtapose the $P A X 3$ or $P A X 7$ gene with FOXO1. The PAX3-FOXO1 fusion protein induces TFAP2B, which is its direct downstream effector and drives aRMS growth by anti-apoptotic signals. ${ }^{9}$ Fluorescence in situ hybridization (FISH) for FOXO1 rearrangement and/or immunohistochemical detection of TFAP2B/AP- $2 \beta$ with the $\mathrm{H}-87$ antibody is recommended for the diagnosis of aRMS. ${ }^{8,12}$

Regarding AP-2 transcription factors in the mammary gland and breast cancer (BC), most studies have focused on TFAP2A/AP- $2 \alpha$ and TFAP2C/AP- $2 \gamma \cdot{ }^{13-19}$ In the normal mammary epithelium, TFAP2A/AP- $2 \alpha$ is expressed throughout the luminal epithelial cell layer, while TFAP2C/AP- $2 \gamma$ is confined to myoepithelial cells. ${ }^{16}$ In BC, TFAP2C (chromosome 20q13) is occasionally co-amplified with HER2 (chromosome 17q21) and these tumors are addicted to TFAP2C/AP- $2 \gamma$ expression. ${ }^{19}$ In estrogen receptor (ER)positive/HER2-negative BC, TFAP2C/AP- $2 \gamma$ is inducible through estrogenic stimulation and represses the cyclindependant kinase inhibitor $C D K N 1 \mathrm{~A} / \mathrm{p} 21^{\text {waf }}$ by direct interaction with the CDKN1A promoter. ${ }^{15,17,18}$ Thereby, TFAP2C/ AP- $2 \gamma$ supports estrogen-dependent cell proliferation. ${ }^{18}$ Enhanced expression of TFAP2C/AP-2 $\gamma$, detected by immunohistochemistry, is an independent predictor of poor patient outcome following anti-hormone monotherapy. ${ }^{17}$ Compared with TFAP2C/AP- $2 \gamma$, little is known about TFAP2B/AP- $2 \beta$ expression in the mammary gland. However, various prognostic BC gene expression signatures, such as the 496 intrinsic gene set, include TFAP2B as a classifier gene. ${ }^{20-25}$ Moreover, we have recently observed strongly enhanced TFAP2B expression in a cell line derived from a human infiltrating lobular BC (ILBC). ${ }^{26}$ Although TFAP2B/AP-2 $\beta$ is an established oncogenic factor and diagnostic marker for aRMS, ${ }^{8,9}$ its role in other tumor entities has remained essentially unexplored. This study investigates TFAP2B/AP- $2 \beta$ expression and function with special reference to breast cancer.

\section{MATERIALS AND METHODS}

\section{Tissue Specimens}

Formalin-fixed, paraffin-embedded (FFPE) tissues included: (i) $n=328$ adult normal tissues corresponding to $n=41$ different tissue types and $n=244$ benign/malignant tumors corresponding to $n=31$ different entities, all compiled on tissue microarrays (TMAs) (Supplementary Figure 1), (ii) $n=99$ whole-slide sections representing normal mammary gland, various reactive changes, pre-invasive neoplastic lesions and invasive $\mathrm{BC}$, obtained from reduction mammoplasties and surgery for BC (Table 1), (iii) $n=183$ previously characterized human primary BCs from the Hannover Medical School, compiled on TMAs (MHH cohort) (Supplementary Table 1), ${ }^{27}$ (iv) $n=2232$ human primary ER-positive/HER2-negative ductal (BC of the unspecific type according to the WHO) or lobular BCs from the West German Study Group's (WSG) clinical trial 'PlanB' (NCT01049425), ${ }^{28}$ compiled on TMAs (Supplementary Table 2), (v) $n=114$ mouse tissue specimens including normal mammary gland and various mouse BCs from six different genetically engineered models (GEMs) (Supplementary Table 3). ${ }^{29-32}$ Moreover, tissue specimens

Table 1 AP-2 $\beta$ expression in various reactive and neoplastic mammary gland lesions

\begin{tabular}{|c|c|c|c|c|}
\hline Staining intensity staining distribution & Specimens & $\begin{array}{l}\text { Negative uniform } \\
\text { (IRS 0-2) }\end{array}$ & $\begin{array}{l}\text { Weak/mod./strong } \\
\text { scattered (IRS 3-9) }\end{array}$ & $\begin{array}{l}\text { Strong uniform } \\
\text { (IRS 12) }\end{array}$ \\
\hline Normal & 15 & 0 & 15 & 0 \\
\hline Secretory metaplasia ${ }^{a}$ & 1 & 0 & 1 & 0 \\
\hline Apocrine metaplasia & 11 & 0 & 0 & 11 \\
\hline Usual ductal hyperplasia & 3 & 0 & 2 & 1 \\
\hline Gynecomastia & 4 & 0 & 3 & 1 \\
\hline Fibroadenoma & 12 & 0 & 3 & 9 \\
\hline Benign phyllodes tumor & 3 & 0 & 1 & 2 \\
\hline Low grade ductal carcinoma in situ & 12 & 3 & 7 & 2 \\
\hline High grade ductal carcinoma in situ & 9 & 4 & 3 & 2 \\
\hline Invasive ductal breast cancer & 6 & 1 & 2 & 3 \\
\hline Lobular carcinoma in situ & 19 & 0 & 3 & 16 \\
\hline Invasive lobular breast cancer & 4 & 0 & 0 & 4 \\
\hline Total & 99 & 8 & 40 & 51 \\
\hline
\end{tabular}

Abbreviation: IRS, immunoreactivity score.

apregnancy related. 
included fresh-frozen and formalin-fixed paraffin-embedded samples of an aRMS harboring a FOXO1 rearrangement and a human whole-mount embryo (8 weeks gestational age) obtained with a hysterectomy in graviditate (undertaken for a large uterine leiomyoma). All human tissue specimens were retrieved from the tissue archive of the Hannover Medical School (MHH) according to the guidelines of the local ethics committee.

\section{Immunohistochemistry and TMAs}

Tissue microarrays containing $1.4 \mathrm{~mm}$ (diameter) core biopsies from representative areas of standard FFPE tissue blocks were constructed as described previously. ${ }^{27,33}$ For detection of AP- $2 \beta, 4 \mu \mathrm{m}$ sections of TMAs or FFPE tissue blocks were mounted on superfrost slides (Thermo Fisher Scientific, Waltham, MA, USA). Slides were deparaffinized and rehydrated conventionally. Staining was performed on a Benchmark Ultra (Ventana, Tucson, AZ, USA) automated stainer using the $\mathrm{CC} 1$ mild protocol for antigen retrieval, the rabbit polyclonal anti-AP- $2 \beta$ antibody H-87 (1:250, Santa Cruz Biotechnology, Dallas, TX, USA $)^{8}$ and the ultraView $\mathrm{DAB}$ kit (Ventana) for signal detection. Nuclear AP-2 $\beta$ staining was evaluated using an immunoreactivity score (IRS) as described by Remmele and Stegener. ${ }^{34}$ Tumors with an IRS $\leq 2$ were considered as AP- $2 \beta$-negative, whereas those with an IRS $\geq 3$ were considered AP- $2 \beta$ positive. Additional antibodies and staining protocols are detailed in Supplementary Tables 4 and 5 .

\section{Double Immunofluorescence}

For AP-2 $2 / \mathrm{p} 63$ double immunofluorescence staining, $2 \mu \mathrm{m}$ sections of FFPE tissue blocks were deparaffinized and rehydrated conventionally and were incubated with the rabbit polyclonal anti-AP- $2 \beta$ antibody H-87 (1:100, Santa Cruz Biotechnology) and the mouse monoclonal anti-p63 antibody 4A4 (1:100, Zytomed Systems, Berlin, Germany). After blocking with $3 \%$ bovine serum albumin (BSA) in phosphate-buffered saline (PBS), slides were incubated with secondary goat anti-rabbit antibodies labeled with Alexa Fluor 488 and goat anti-mouse antibodies labeled with Alexa Fluor 546. Cells were counterstained with Hoechst $33342(1 \mu \mathrm{g} / \mathrm{ml}$, Thermo Fisher Scientific). Visualization was performed with the Mantra Qualitative Pathology Workstation (PerkinElmer, Waltham, MA, USA).

\section{Quantitative Real-Time RT-PCR}

Extraction of total RNA from FFPE BC specimens and BC cell lines was performed as described previously. ${ }^{27}$ The cDNA synthesis was carried out with MultiScribe reverse transcriptase (Applied Biosystems, Foster City, USA). Quantitative assessment of gene expression normalized to two housekeeping genes (GUSB and TBP) was performed with Platinum Taq DNA polymerase (Invitrogen, Carlsbad, CA, USA), Sybr Green I (Thermo Fisher Scientic) and QuantiTect ${ }^{\circledR}$ primer assays (Qiagen, Hilden, Germany) on an ABI Prism 7700 system (Applied Biosystems). Significance of gene expression differences was determined with the Mann-Whitney test and GraphPad Prism software (version 5.00, La Jolla, CA, USA).

\section{Fluorescence In Situ Hybridization}

For FISH, $4 \mu \mathrm{m}$ sections of FFPE tissue blocks were mounted on superfrost slides. FISH was performed using a commercially available break-apart dual color probe for the FOXO1 gene (Zytolight Spec FOXO1 Dual Color Break Apart Probe, Zytovision, Bremerhaven, Germany) according to the manufacturer's instructions. One hundred non-overlapping tumor cells were examined for split signals using an Axio Imager Z1 fluorescence microscope (Zeiss, Oberkochen, Germany).

\section{Cell Culture}

The human BC cell lines MDA-MB-134, MDA-MB-361, UACC-893, BT-474, CAL-51, and IPH-926 have been described previously. ${ }^{35-38}$ All cell lines were authenticated by short tandem repeat profiling. ${ }^{39}$ MDA-MB-134 and IPH-926 cells were additionally authenticated by detection of their unique, homozygous $C D H 1$ mutations, as described previously. ${ }^{40}$ All cell lines were routinely cultured in RPMI-1640 medium supplemented with 10\% fetal calf serum, $10 \mu \mathrm{g} / \mathrm{ml}$ bovine insulin, $2.5 \mathrm{~g} / \mathrm{l}$ glucose, $1 \mathrm{mM}$ sodium pyruvate, $2 \mathrm{mM}$ glutamine, and $10 \mathrm{mM}$ HEPES, in a watersaturated atmosphere containing $5 \% \mathrm{CO}_{2}$ at $37.5^{\circ} \mathrm{C}$. Cell cultures were routinely surveyed to rule out mycoplasma contamination using a PCR-based detection system, as described by Uphoff et al. ${ }^{41}$ For assessment of a potential ER-dependent modulation of TFAP2B expression, estrogenresponsive $\mathrm{BC}$ cells were treated with the ER-antagonist ICI 182,780 (Fulvestrant, Tocris, Bristol, UK) at $1 \mu \mathrm{M}$ for $48 \mathrm{~h}$, as described previously. ${ }^{27}$ For assessment of a potential E-Cadherin-dependent modulation of TFAP $2 B$ expression, E-cadherin-defective IPH-926 cells were transiently transfected with the p-wtEcad-EGFP-N2 expression construct encoding for full-length wild-type human E-cadherin fused to the cDNA sequence of EGFP, as described previously. ${ }^{42,43}$ Transfection reactions were carried out with Lipofectamine 2000 (Invitrogen) according to manufacturer's recommendations. For inhibition of AP- $2 \beta$ protein expression, $\mathrm{BC}$ cells were exposed to small interfering RNAs (siRNAs) targeting TFAP2B (si-TFAP2B, SMARTpool ON-TARGETplus, Dharmacon, Lafayette, CO, USA). In brief, cells were seeded in 24 well plates at a density of $5 \times 10^{4}$ cells per well and were allowed to adhere overnight. Next, transient transfection of siTFAP2B $(25 \mathrm{nM})$ was performed with Dharmafect 2 Transfection Reagent (Dharmacon) according to the manufacturer's recommendations. Knockdown of AP- $2 \beta$ protein expression was confirmed by Western blot $72 \mathrm{~h}$ after the onset of transfection. As a control, cells were transfected with pooled non-targeting siRNAs (si-con, ON-TARGETplus Non-targeting Pool, Dharmacon). 


\section{Affymetrix Gene Expression Data}

Affymetrix U133Plus2.0 GeneChip raw data of $n=20$ human BC cell lines (GEO GSE28089, GSE12777) were compiled and analyzed for TFAP2 family members using Expression Console and BRB-array tools software as described previously. ${ }^{26}$

\section{Western Blot}

Cells were lysed in RIPA buffer. $20 \mu \mathrm{g}$ total cellular proteins were separated by $12 \%$ SDS-PAGE and were transferred to nitrocellulose membranes. Membranes were probed with anti-AP-2 $\beta$ (H-87, 1:1000, Santa Cruz Biotechnology) and anti- $\beta$-actin antibodies (AC15, 1:2000, Acris, Hiddenhausen, Germany) as described previously. ${ }^{44}$ Lysates of $293 \mathrm{~T}$ cells transfected with TFAP2B, TFAP2A, TFAP2C expression plasmids obtained comercially served as controls (sc113759, sc-113722, sc-116386, Santa Cruz Biotechnology).

\section{Cell Viability Assay}

Relative cell proliferation was determined with the WST-1 assay (Roche, Mannheim, Germany) in 96-well culture plates as described previously. ${ }^{40}$ For cell cycle analysis, cells were fixed in 70\% ice-cold ethanol and were treated by RNAase A
(50 mg/ml; Roche). Cells were stained in PBS/2 mM EDTA/ $0.1 \%$ Triton-X-100 containing $20 \mathrm{mg} / \mathrm{ml}$ propidium iodide (Sigma, Deisenhofen, Germany) $30 \mathrm{~min}$ before analysis on FACS Calibur flow cytometer. ${ }^{40}$

\section{Statistics}

Association of AP- $2 \beta$ expression with clinicopathological factors in primary $\mathrm{BC}$ specimens was assessed using the $\chi^{2}$-test, the $\chi^{2}$-test for trends, Fisher's exact test and GraphPad Prism software (version 5.00). Event-free survival was analyzed using log-rank test (Mantel-Cox) and SPSS (version 23).

\section{RESULTS}

$\mathbf{H - 8 7}$ is Suitable for Specific Immunodetection of AP-2 $\boldsymbol{\beta}$

To confirm the specificity of the H-87 anti-AP- $2 \beta$ antibody, $293 \mathrm{~T}$ cells transfected with TFAP2A, TFAP2B, or TFAP2C were analyzed by immunoblotting. The $\mathrm{H}-87$ antibody reacted only with 293 T-TFAP2B cell lysate (Figure 1a). Next, H-87 immunoreactivity was assessed in an aRMS. FOXO1 rearrangement was confirmed by FISH. Immunoblotting of fresh-frozen tissue revealed a strong protein band of $\sim 50 \mathrm{kDa}$ (Figure 1b). This is consistent with the molecular weight of a

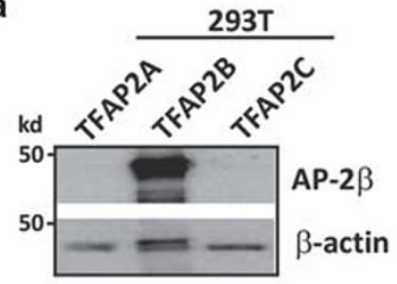

b

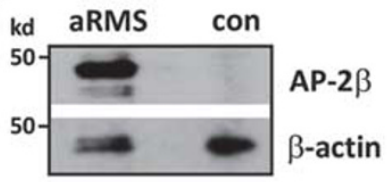

c

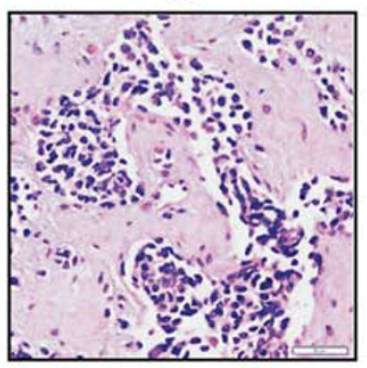

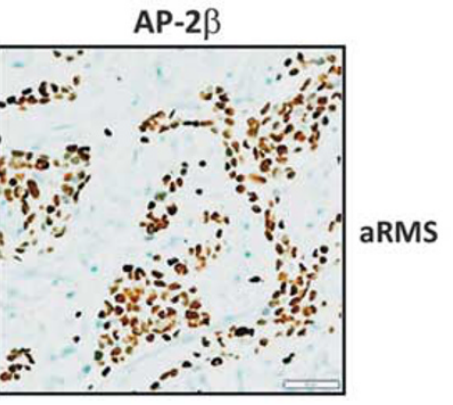

d

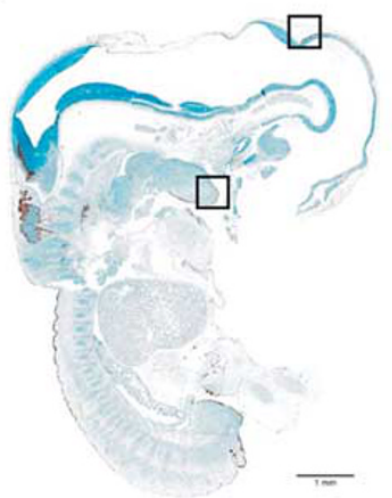

e

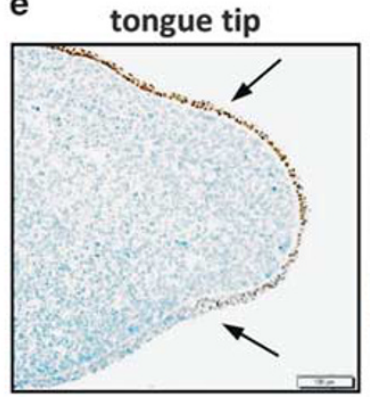

mid brain

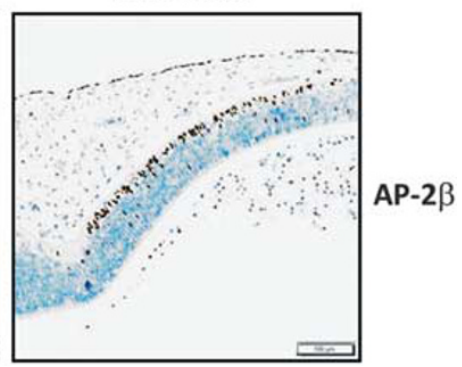

Figure 1 Specific immunodetection of AP-2 3 . (a) Immunoblotting of $293 \mathrm{~T}$ cells transfected TFAP2A, TFAP2B, or TFAP2C. Total cellular protein was separated by $12 \%$ SDS-PAGE and was probed with the anti-AP- $2 \beta$ antibody $\mathrm{H}-87$. Detection of $\beta$-actin verified equal loading. (b) Immunoblotting of fresh-frozen tissue of an aRMS harboring a FOXO1 rearrangement with the $\mathrm{H}-87$ antibody. (c) Immunostaining of FFPE tissue of the same aRMS with the $\mathrm{H}-87$ antibody. (d) Immunostaining of a human FFPE whole-mount embryo (8 weeks gestational age) with the H-87 antibody. (e) Selected details of the immunostained whole-mount embryo. Note that AP- $2 \beta$ immunoreactivity is evident in the upper-side epithelium of the tongue, but spares the lower side epithelium of the tongue, which is consistent with previously reported embryonic TFAP2B mRNA expression pattern. ${ }^{2}$ 
AP- $2 \beta(47 \mathrm{kDa})$ and its aberrant overexpression in FOXO1rearranged aRMS. ${ }^{8,9,12}$ Immunostaining of FFPE tissue of this aRMS showed strong nuclear reactivity, which is in line with the function of AP- $2 \beta$ as a transcription factor (Figure 1c). To further demonstrate the utility of the H-87 antibody, a human FFPE whole-mount embryo (8 weeks gestational age) was subjected to immunostaining (Figure 1d). Immunoreactive tissues matched with the known embryonic TFAP2B expression pattern. In detail, H-87 immunoreactivity was observed in embryonic epidermis, renal tubules, facial mesenchyme, mid brain and in the oral cavity mucosa, including the upper but not the lower side of the tongue (Figure 1e). ${ }^{2}$ This is consistent with previous data obtained by mRNA in situ hybridization (Supplementary Table 6). ${ }^{2}$ Taken together, $\mathrm{H}-87$ is suitable for specific immunodetection of AP- $2 \beta$ protein in FFPE tissues.

\section{AP-2 $\beta$ Expression is Limited to Few Adult Normal Tissues and Tumor Entities}

Next, $n=41$ different human adult normal tissue types and $n=31$ related tumor entities were screened for AP- $2 \beta$ expression using TMAs (Supplementary Figure 1). AP-2 $\beta$ positive tissues included mammary gland, kidney, salivary gland, epidermis and squamous epithelium of the esophagus. In the epidermis and esophagus, nuclear AP- $2 \beta$ expression was confined to the basal epithelial cell layer (Supplementary Figure 1). Very faint, cytoplasmic immunoreactivity was occasionally observed in endothelial cells, and was considered unspecific. As expected, AP- $2 \beta$-positive tumor entities included aRMS, but also pleomorphic adenoma of the salivary gland and basal cell carcinoma of the skin. Variable AP- $2 \beta$ expression was observed in invasive BCs. Hence, AP- $2 \beta$ expression was limited to comparatively few adult normal tissues and tumor entities ( $<15 \%$ of those tested), including the mammary gland and BC.

\section{AP-2 $\beta$ Expression in the Normal Mammary Gland and in Pre-Invasive Neoplastic Lesions}

To characterize AP- $2 \beta$ expression in the mammary gland in more detail, $n=99$ breast whole-slide sections ranging from normal histology to reactive changes, pre-invasive neoplastic lesions and invasive $\mathrm{BC}$ were selected for immunohistochemistry (Table 1). The normal epithelium of both ducts and lobules showed a scattered staining pattern (Figure 2a). Approximately one third of mammary epithelial cells stained positive for AP- $2 \beta$ (labeling fraction $0.32 \pm 0.11$ ). A subset of strongly AP- $2 \beta$-positive cells was interspersed in the luminal cell layer or was positioned between luminal and basal cells (Figure 2a). Weak immunoreactivity was also seen in some cells of the basal cell layer. However, the strongly AP- $2 \beta$ positive mammary epithelial cells clearly lacked the myoepithelial marker p63, as determined by double immunofluorescence staining (Figure $2 \mathrm{~b}$ ). Enhanced AP- $2 \beta$ expression in terms of an expansion of AP- $2 \beta$-positive cells was evident in various reactive, metaplastic and benign lesions. These included apocrine metaplasia, usual ductal hyperplasia, the epithelium of fibroadenomas and benign phyllodes tumors, but not pregnancy-related secretory transformation (Figure 3). All nineteen (19/19) lobular carcinomas in situ (LCIS) were AP- $2 \beta$-positive, but seven of twenty-one (7/21) ductal carcinomas in situ (DCIS) were AP- $2 \beta$-negative $(P<0.001)$ (Table 1). Likewise, invasive lobular breast cancer (ILBC) showed a strong and uniform AP- $2 \beta$ immunoreactivity in all nuclei, corresponding to an IRS of 12 , while invasive ductal breast cancer (IDBC, $\mathrm{BC}$ of the unspecific type according to the $\mathrm{WHO}$ ) showed variable staining
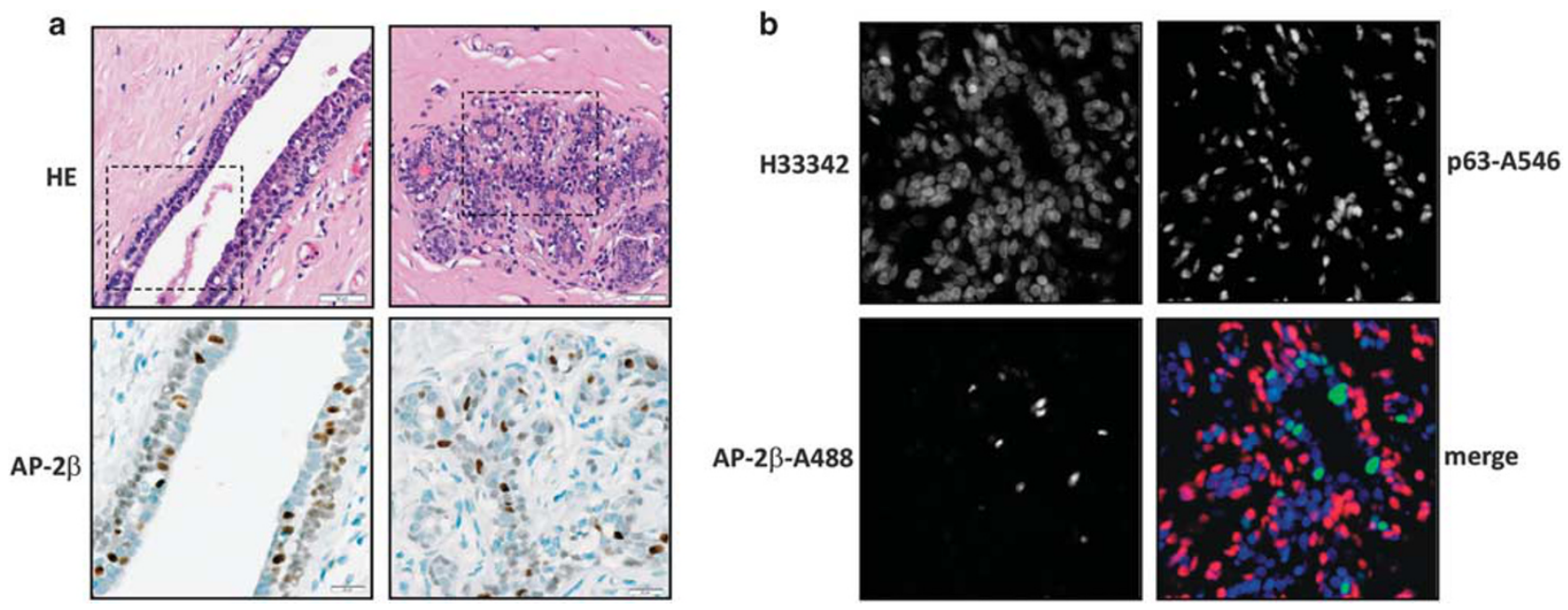

Figure 2 AP-2 $\beta$ expression in the normal mammary gland. (a) Scattered AP-2 $\beta$-positive cells in the epithelium of mammary gland duct (left panel) and a mammary gland lobule (right panel). (b) Double immunofluorescence staining of a terminal ductal lobular unit for the myoepithelial marker p63 and AP- $2 \beta$. The mouse monoclonal anti-p63 antibody 4A4 was detected with an A546-conjugated secondary anti-mouse antibody (red). The rabbit polyclonal anti-AP- $2 \beta$ antibody $\mathrm{H}-87$ was detected with an A488-conjugated secondary anti-rabbit antibody (green). 

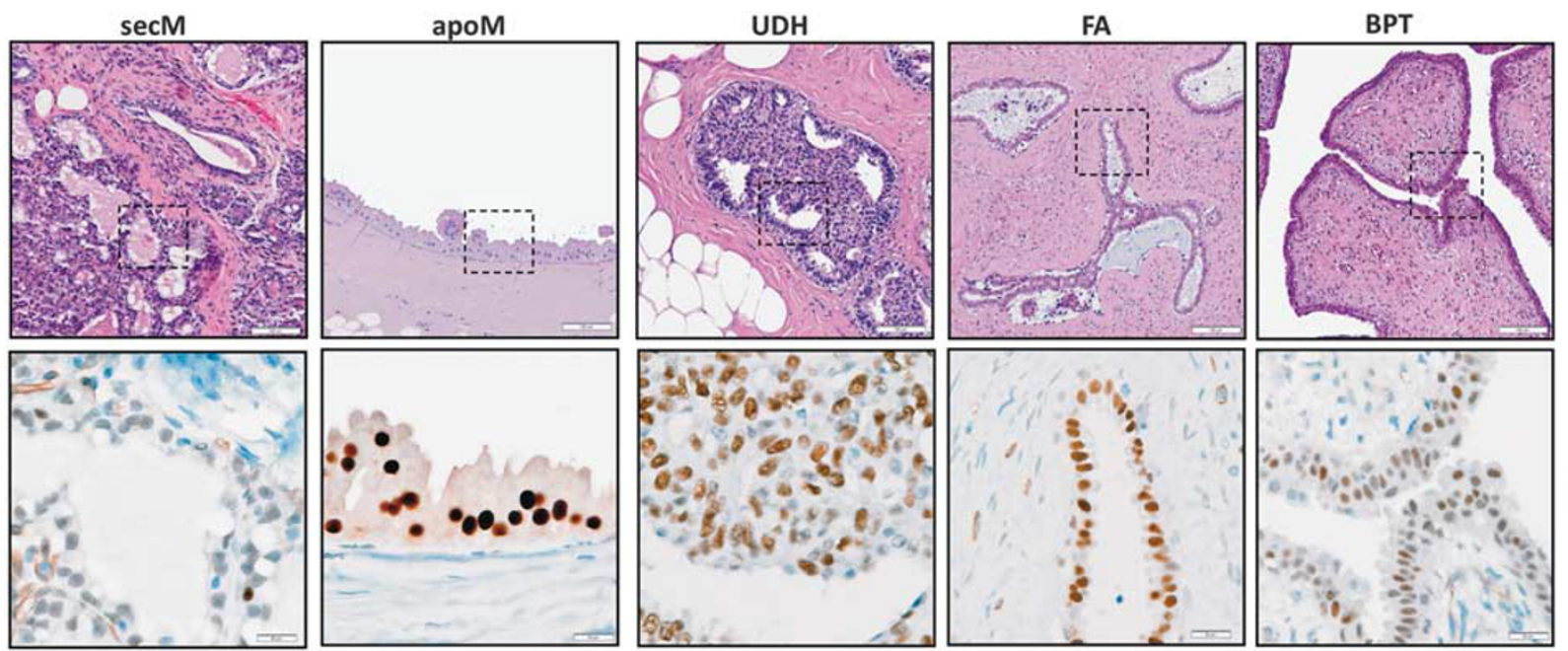

HE
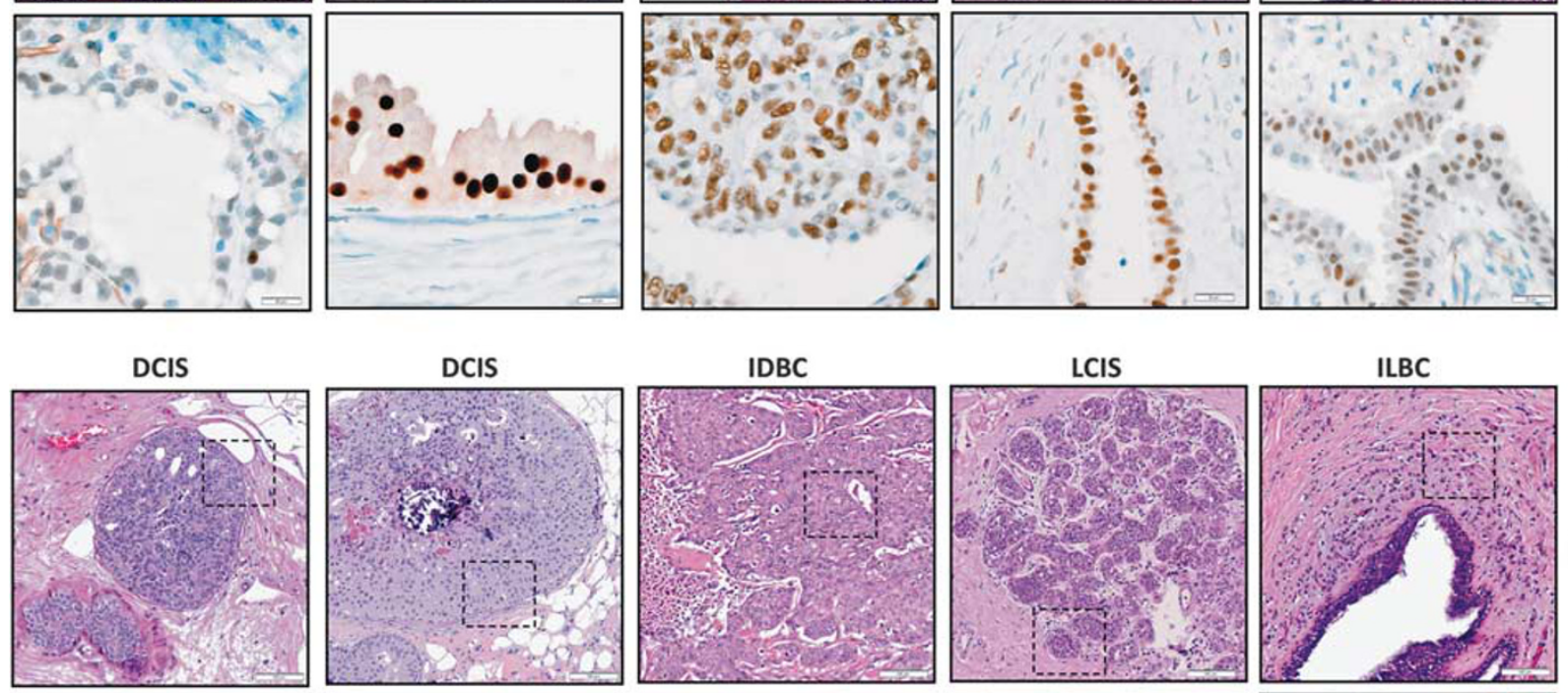

HE
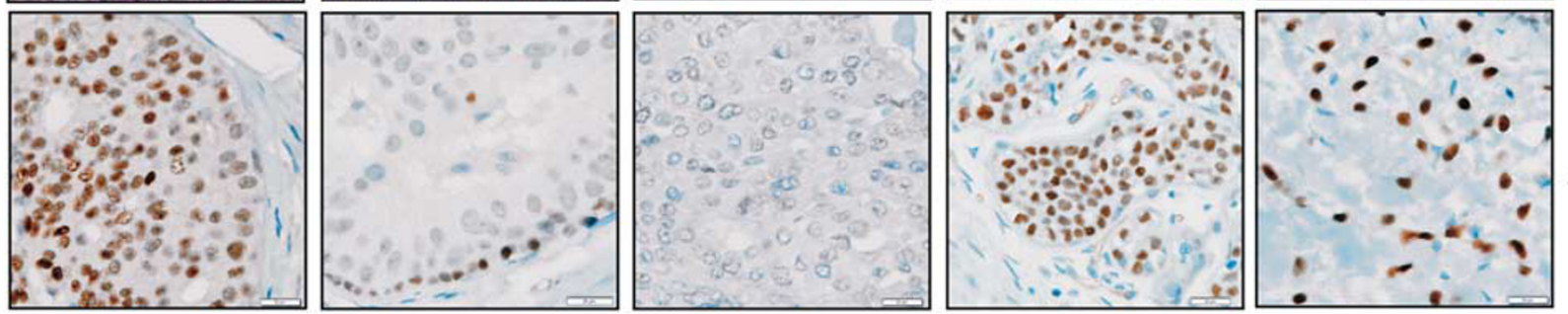

AP-2 3

Figure 3 Enhanced AP- $2 \beta$ expression in various reactive, metaplastic, benign and pre-invasive neoplastic mammary gland lesions. HE-stained sections $(\times 100)$ are shown in the top panels and $\mathrm{H}$-87-stained sections $(\times 400)$ are shown in the bottom panels. apoM, apocrine metaplasia; BPT, benign phyllodes tumor; DCIS, ductal carcinoma in situ; FA, fibroadenoma; IDBC, invasive ductal breast cancer (BC of the unspecific type according to the WHO); ILBC, invasive lobular breast cancer; LCIS, lobular carcinoma in situ; SecM, pregnancy-related secretory transformation; UDH, usual ductal hyperplasia.

characteristics (Figure 3). Occasionally, the normal mammary epithelium adjacent to invasive $\mathrm{BC}$ showed a marked luminal expansion of AP-2 $\beta$-positive cells (Figure 4).

\section{AP-2 $\beta$ is Associated with ILBC and Prolonged Event-Free Survival in Clinical BC Cohorts}

Next, AP- $2 \beta$ was assessed in two clinical cohorts of invasive $\mathrm{BC}$ compiled on TMAs. The first collection (MHH cohort) included $n=183$ primary BCs (Supplementary Table 1). Using an IRS of $\geq 3$ as a cutoff to define AP- $2 \beta$-positivity, $61 \%$ of $\mathrm{BCs}$ were AP- $2 \beta$-positive (Figure $5 \mathrm{a}$ ). A positive AP- $2 \beta$ status was associated with ILBC $(P<0.001)$ (Table 2). Moreover, AP- $2 \beta$ expression was associated with a positive ER, AR, and BCL2 status, a low Ki67 index, loss of E-cadherin, lack of CK5/14 and absence of nuclear p53 accumulation (Figure 5a; Table 2). Similar results were obtained using different IRS cutoffs to define AP- $2 \beta$-positivity (data not shown). To substantiate these findings, a subset of $n=26$ cases of this series was subjected to quantitative realtime RT-PCR confirming higher TFAP2B mRNA expression in AP- $2 \beta$-positive cases (Figure $5 \mathrm{~b}$ ). Quantitative real-time RT-PCR also confirmed higher TFAP2B mRNA expression in ILBC compared with normal mammary gland tissue and IDBC (Figure 5b).

Features associated with $\mathrm{AP}-2 \beta$ in the $\mathrm{MHH}$ cohort were characteristic for the luminal molecular BC subtype. As most ILBCs belong to the luminal subtype, ${ }^{22,45,46}$ association of AP- $2 \beta$ with ILBC may rather reflect the restricted molecular diversity of this special tumor entity. To test this, AP- $2 \beta$ was evaluated in a second clinical cohort of invasive BCs comprising $>3000$ cases analyzed for disease-free survival as the official study endpoint (WSG PlanB trial). ${ }^{47}$ Of note, only ER-positive/HER2-negative BCs of either ductal or lobular histological type with available AP- $2 \beta$ status 


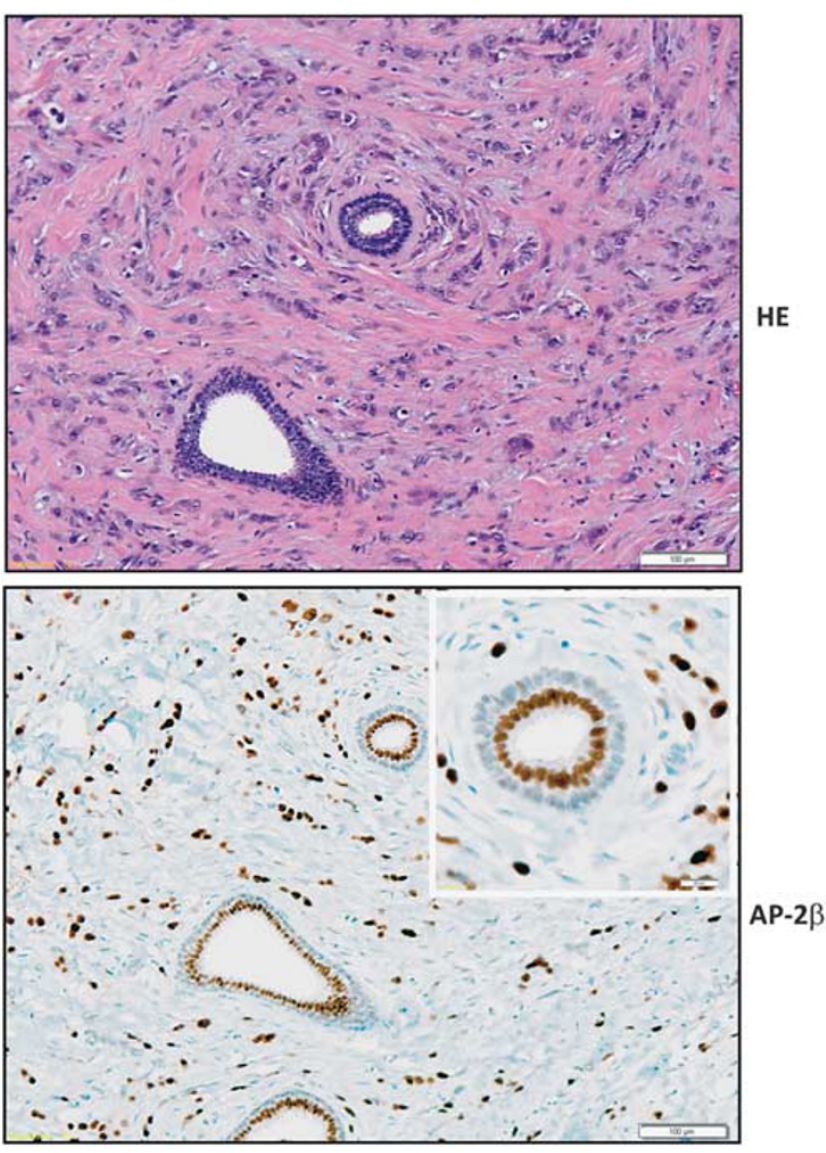

Figure 4 Enhanced AP-2 $\beta$ expression in the normal mammary epithelium adjacent to ILBC. Please note that invasive tumor cells and the entire luminal cell layer of the adjacent normal mammary duct show an intense $\mathrm{H}-87$ immunoreactivity (inset).

$(n=2232) \quad$ were retained for this refined analysis (Supplementary Table 2). Again, AP-2 $\beta$-positivity was associated with ILBC $(P<0.001)$ (Table 3$)$. A significant association of AP- $2 \beta$-positivity with ILBC was also observed, if the $\mathrm{BC}$ samples were limited to ER-positive/HER2-negative cases with a Ki67 index of $\leq 10 \%$, which corresponds to the luminal-A BC subset (data not shown). Moreover, AP- $2 \beta$ was associated with a pN0 status, low Ki67 index and low/ intermediate Oncotype-DX recurrence scores (all $P<0.001$ ) (Table 3 ). In a preliminary analysis of clinical follow-up data available for $n=1747$ enrolled patients (univariate analysis, median follow-up of 34 months, without delimitation of treatment modalities), AP- $2 \beta$ was associated with prolonged event-free survival $(P=0.003)$ (Figure $5 \mathrm{c})$. Interestingly, the relationship between histological grade and $\mathrm{AP}-2 \beta$ expression was different for ILBC and IDBC. In IDBC, AP- $2 \beta$-positivity rates declined with higher histological grade (Figure $5 \mathrm{~d}$ ). In ILBC, AP- $2 \beta$-positivity rates remained at a high level in poorly differentiated (G3) cases (Figure 5d). Consistently, AP- $2 \beta$-positivity was associated with prolonged event-free survival only in IDBC $(P=0.004)$, but not ILBC $(P=0.292)$ (Supplementary Figure 2).

\section{Lack of AP-2 $\beta$ Expression in BCs from GEM Models}

The anti-AP- $2 \beta$ antibody $\mathrm{H}-87$ was raised against amino acids $130-216$ of the AP- $2 \beta$ protein. This protein domain shows $100 \%$ homology between human and mouse AP- $2 \beta$. Hence, $\mathrm{H}-87$ is also suitable for immunodetection of mouse AP- $2 \beta$. The mammary epithelium of juvenile and adult female mice showed interspersed AP- $2 \beta$-positive cells. These staining characteristics resembled the human mammary gland. However, $\mathrm{n}=104$ mouse BCs from six different GEM models (Wsv40-T-ag, MMTVcre;Pik3ca ${ }^{\text {H1047R }}, \quad$ Wcre;Pik3ca ${ }^{H 1047 R}$, Wcre; Trp $53^{F / F}$, Wcre;Trp $53^{F / F} ; C d h 1^{F / F}$, Wcre; $C d h 1^{F / F} ;$ Pten $^{F / F}$ ) were all AP-2 $\beta$-negative, including mouse lobular carcinomas (Supplementary Figure 3).

\section{AP-2 $\beta$ Expression in Human BC Cell Lines}

Next, human BC cell lines were utilized to study AP- $2 \beta$. Based on previously described Affymetrix microarray gene expression data, ${ }^{26,37} n=6 \mathrm{BC}$ cell lines with differential TFAP2B expression were selected for further experiments (Supplementary Figure 4). Consistent with microarray data, quantitative real-time RT-PCR, immunoblotting and immunohistochemistry confirmed TFAP2B/AP- $2 \beta$ expression in MDA-MB-361, MDA-MB-134, and IPH-926, while UACC-893, BT-474 and CAL-51 were TFAP2B/AP-2 $\beta$ negative (Figure $6 \mathrm{a}$ and $\mathrm{b}$ ). Of note, TFAP2B mRNA levels were higher in TFAP2B-positive BC cell lines compared with TFAP2B-positive primary BCs. Consistent with the association of AP- $2 \beta$ with ILBC observed in the two clinical BC cohorts, ILBC cell lines (MDA-MB-134 and IPH-926) were $\mathrm{AP}-2 \beta$-positive (Figures $6 \mathrm{a}$ and $\mathrm{b}$ ).

\section{AP-2 $\beta$ is Independent from ER-Signaling and Contributes to Cell Proliferation}

The association of AP- $2 \beta$ with a positive ER status in primary BCs could be a consequence of ER-dependent transcriptional activation of TFAP2B/AP-2 $\beta$. In fact, TFAP2C/AP- $2 \gamma$, another member of the AP-2 family, is an ER-responsive gene. ${ }^{15}$ To test for an ER-dependent expression of TFAP2B/AP-2 $\beta$, hormone-responsive ER-positive/AP- $2 \beta$-positive $\mathrm{BC}$ cell lines (MDA-MB-361 and MDA-MB-134) were exposed to the ERantagonist ICI 182,780 (Fulvestrant). ICI 182,780 efficiently inhibits expression of ER-responsive genes and thereby blocks cell proliferation. ${ }^{27,48}$ Appropriate cell stimulation with ICI 182,780 was verified by flow cytometric cell cycle analysis, as described previously (data not shown). ${ }^{27}$ However, AP- $2 \beta$ protein expression was not affected by ICI 182,780 (Figure $6 \mathrm{c}$ ). AP- $2 \beta$ protein expression was also not modulated by cell culture density (Figure $6 \mathrm{~d}$ ). Moreover, reconstitution of E-cadherin in ILBC cells did not alter AP- $2 \beta$ expression (Figure 6e). Hence, AP- $2 \beta$ expression is independent from cell culture density, E-cadherin or ER-signaling in human BC cell lines.

In aRMS, AP- $2 \beta$ is an established oncogenic factor, which drives tumor growth by anti-apoptotic signals. ${ }^{9}$ Ebauer et al. reported that siRNA-mediated inhibition of AP- $2 \beta$ induces 
a

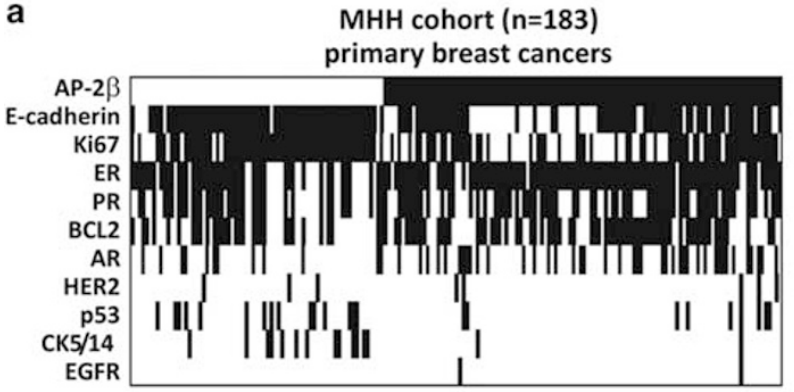

c

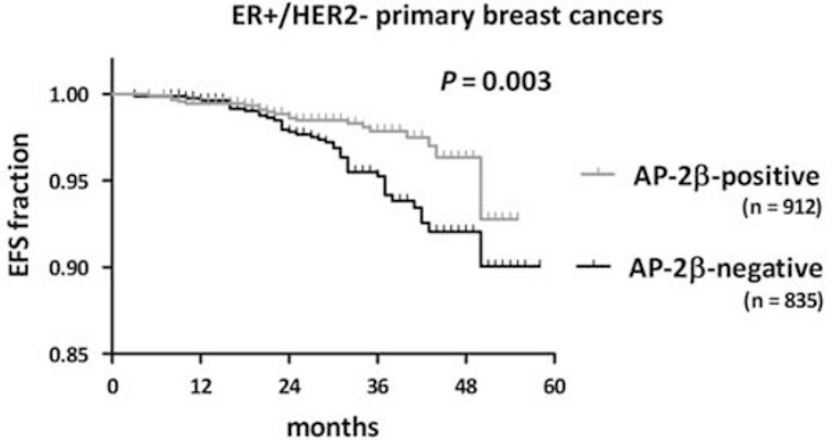

b

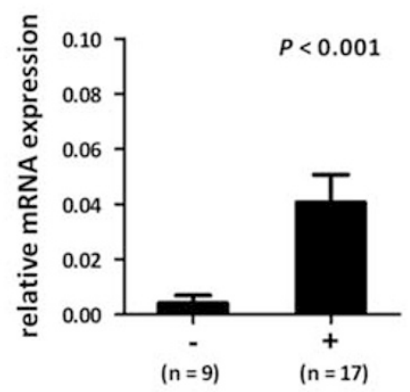

AP2- $\beta$ immunoreactivity

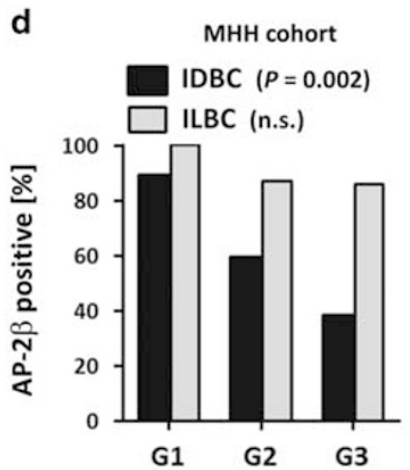

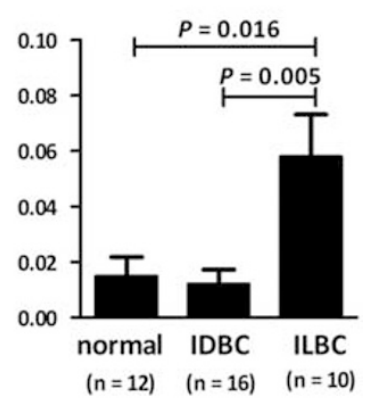

WSG PlanB cohort

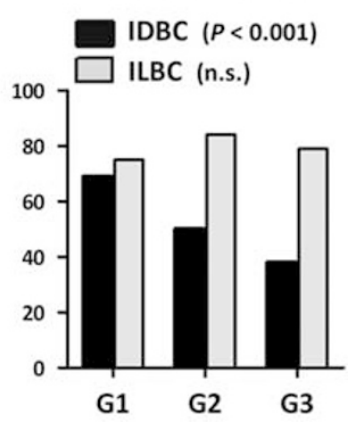

Figure 5 AP- $2 \beta$ expression in primary BC. (a) Diagrammatic presentation of immunophenotypic characteristics of $n=183$ primary BCs of the MHH tumor cohort. Each column represents an individual BC and each row represents an individual immunohistochemical marker. Black indicates positive and white indicates negative. For Ki67, black indicates a labeling index of $>10$ and white indicates a labeling index of $\leq 10$ (b) Higher TFAP2B mRNA expression levels in AP- $2 \beta$-positive compared with AP-2 $\beta$-negative BCs (left panel) and in ILBC compared with IDBC (right panel). A subset of BCs from the MHH cohort was subjected to RNA extraction, CDNA synthesis and quantitative real-time RT-PCR as described in the materials and methods section. Cases included $n=16$ randomly selected IDBCs and $n=10$ randomly selected ILBCs. Normal mammary gland tissue from resections specimens without malignancy $(n=12)$ were also included. Statistical significance was determined with the Mann-Whitney test. (c) Prolonged event-free survival in AP-2 $\beta$ positive BCs in $n=1747$ ER-positive/HER2-negative mammary carcinomas from the WSG PlanB trial. Statistical significance was determined with the logrank test. (d) Relationship between histological grade and AP- $2 \beta$ protein expression in primary BCs from the MHH cohort (left panel) and the WSG PlanB cohort (right panel). Statistical significance was determined by the $\chi^{2}$-test for trends.

apoptosis in aRMS cells in vitro. ${ }^{9}$ To test for a similar function of AP- $2 \beta$ in BC, we sought to study the impact of siRNAs directed against TFAP2B (si-TFAP2B) in human BC cell lines. Immunoblotting confirmed knockdown of $A P-2 \beta$ in response to si-TFAP2B exposure (Figure 7a). As expected, si-TFAP2B exposure did not affect the growth of AP- $2 \beta$-negative $\mathrm{BC}$ cell lines (UACC-893, BT-474, CAL-51). In contrast, si-TFAP2B diminished the growth of all AP- $2 \beta$-positive $\mathrm{BC}$ cell lines tested, including ILBC cell lines (MDA-MB-134 and IPH-926) (Figure 7b). Flow cytometric cell cycle analyses showed that the growth-inhibitory effect of si-TFAP $2 B$ was associated with a marginally increased $G_{0} / G_{1}$-phase fraction and a reduced S-phase fraction, but not with an excess of sub$\mathrm{G}_{1}$ /apoptotic cells (Figure $7 \mathrm{c}$ ). Hence, AP- $2 \beta$ controls cell proliferation, but does not function as an anti-apoptotic factor in BC, as has been reported for aRMS. ${ }^{9}$

\section{DISCUSSION}

Transcription factor TFAP2B/AP- $2 \beta$ regulates embryonic organ development and its aberrant overexpression is implicated in aRMS. ${ }^{8,9,12}$ Little is known about TFAP2B/ $\mathrm{AP}-2 \beta$ expression and function in other tumor entities, including BC. However, TFAP $2 B$ is part of various classifier gene lists devised for $\mathrm{BC}$ subtyping and prognostication. ${ }^{20-25}$ This is the first study which provides a detailed characterization of AP- $2 \beta$ expression and function with special reference to the mammary gland and BC.

Comparatively few adult normal tissues showed AP- $2 \beta$ protein expression. Interestingly, AP- $2 \beta$ was detected in the basal epithelial cell layer of the epidermis and squamous epithelium of the esophagus, suggesting a role of AP- $2 \beta$ in the stem cell compartment in these tissues. In the normal mammary gland, AP- $2 \beta$ showed a scattered expression pattern. Thus, the AP- $2 \beta$ expression pattern differed from the staining pattern reported for AP- $2 \alpha$ (entire luminal cell layer) and AP- $2 \gamma$ (entire myoepithelial cell layer). ${ }^{16}$ Various reactive, metaplastic and pre-invasive neoplastic mammary gland lesions showed enhanced AP- $2 \beta$ expression in terms of an expansion of the AP- $2 \beta$-positive cell population. Previously reported microarray gene expression data have listed 
Table 2 Association of clinicopathological characteristics and AP-2 $\beta$, MHH BC cohort

\begin{tabular}{|c|c|c|c|}
\hline & AP- $2 \beta$ negative & AP- $2 \beta$ positive & P-value \\
\hline Histology & & & $<0.001^{a, b}$ \\
\hline IDBC & $61(48)$ & $67(52)$ & \\
\hline ILBC & $7(14)$ & $42(86)$ & \\
\hline Others & $3(50)$ & $3(50)$ & \\
\hline pT status & & & $0.699^{c}$ \\
\hline pT1 & $39(40)$ & $59(60)$ & \\
\hline pT2 & $21(38)$ & $35(63)$ & \\
\hline pT3 & $4(29)$ & $10(71)$ & \\
\hline pT4 & $7(50)$ & $7(50)$ & \\
\hline pN status & & & $0.248^{\mathrm{a}}$ \\
\hline pNO & $33(35)$ & $62(65)$ & \\
\hline $\mathrm{pN1+}$ & $29(45)$ & $36(55)$ & \\
\hline Histological grade & & & $<0.001^{c}$ \\
\hline G1 & $1(7)$ & $14(93)$ & \\
\hline G2 & $34(32)$ & $72(68)$ & \\
\hline G3 & $34(58)$ & $28(42)$ & \\
\hline$E R$ & & & $<0.001^{\mathrm{a}}$ \\
\hline Negative & $25(69)$ & $11(31)$ & \\
\hline Positive & $46(31)$ & $101(69)$ & \\
\hline$P R$ & & & $0.284^{\mathrm{a}}$ \\
\hline Negative & $34(44)$ & $44(56)$ & \\
\hline Positive & $37(35)$ & $68(65)$ & \\
\hline$A R$ & & & $0.002^{\mathrm{a}}$ \\
\hline Negative & $47(49)$ & $49(51)$ & \\
\hline Positive & $12(23)$ & $41(77)$ & \\
\hline HER2 & & & $0.822^{c}$ \\
\hline $0,1+$ & $66(38)$ & $106(62)$ & \\
\hline $2+($ FISH neg.) & $2(67)$ & $1(33)$ & \\
\hline $3+$ & $3(38)$ & $5(63)$ & \\
\hline p53 & & & $0.014^{\mathrm{a}}$ \\
\hline Negative & $56(35)$ & $103(65)$ & \\
\hline Positive & $15(63)$ & $9(38)$ & \\
\hline$B C L 2$ & & & $0.033^{\mathrm{a}}$ \\
\hline Negative & $40(48)$ & $44(52)$ & \\
\hline Positive & $31(31)$ & $68(69)$ & \\
\hline CK5/14 & & & $<0.001^{\mathrm{a}}$ \\
\hline Negative & $58(35)$ & $110(65)$ & \\
\hline Positive & $13(87)$ & $2(13)$ & \\
\hline E-cadherin & & & $<0.001^{\mathrm{a}}$ \\
\hline Negative & $7(13)$ & $45(87)$ & \\
\hline Positive & $64(49)$ & $67(51)$ & \\
\hline$E G F R$ & & & $0.523^{\mathrm{a}}$ \\
\hline Negative & $71(39)$ & $110(61)$ & \\
\hline Positive & $0(0)$ & $2(100)$ & \\
\hline
\end{tabular}

Table 2 Continued

\begin{tabular}{lccc}
\hline & AP-2 $\beta$ negative & AP-2 $\beta$ positive & P-value \\
\hline Ki67 & $6(14)$ & & \\
$<5 \%, 5 \%$ & $18(30)$ & $36(86)$ & $<0.001^{c}$ \\
$10 \%, 15 \%$ & $20(59)$ & $14(70)$ & \\
$20 \%, 25 \%$ & $6(43)$ & $8(57)$ & \\
$30 \%, 35 \%$ & $21(66)$ & $11(34)$ & \\
$40 \%,>40 \%$ & & & \\
\hline
\end{tabular}

Numbers in parentheses indicate percentages.

${ }^{a} x^{2}$-test.

${ }^{\mathrm{b}}$ Other histological types were excluded.

${ }^{2} X^{2}$-test for trends.

Table 3 Association of clinicopathological characteristics and AP-2 $\beta$, WSG PlanB BC cohort

\begin{tabular}{|c|c|c|c|}
\hline & AP- $2 \beta$ negative & AP- $2 \beta$ positive & P-value \\
\hline \multicolumn{4}{|l|}{ Histology } \\
\hline IDBC & $981(51)$ & $942(49)$ & $<0.001^{\mathrm{a}}$ \\
\hline ILBC & $64(21)$ & $245(79)$ & \\
\hline \multicolumn{4}{|l|}{ pT status } \\
\hline pT1 & $485(45)$ & $593(55)$ & $0.017^{a}$ \\
\hline pT2-4 & $453(50)$ & $446(50)$ & \\
\hline \multicolumn{4}{|l|}{$p N$ status } \\
\hline pNO & $571(43)$ & $746(57)$ & $<0.001^{b}$ \\
\hline pN1 & $394(50)$ & $391(50)$ & \\
\hline pN2 & $64(65)$ & $35(35)$ & \\
\hline pN3 & $16(52)$ & $15(48)$ & \\
\hline Histological grade & & & $<0.001^{b}$ \\
\hline G1 & $22(22)$ & $78(78)$ & \\
\hline G2 & $597(43)$ & $805(57)$ & \\
\hline G3 & $426(58)$ & $304(42)$ & \\
\hline$P R$ & & & $0.419^{a}$ \\
\hline Negative & $195(49)$ & $204(51)$ & \\
\hline Positive & $841(46)$ & $968(54)$ & \\
\hline Ki67 & & & $<0.001^{b}$ \\
\hline$<5 \%, 5 \%$ & $166(35)$ & $313(65)$ & \\
\hline $10 \%, 15 \%$ & $391(45)$ & $481(55)$ & \\
\hline $20 \%, 25 \%$ & $302(54)$ & $258(46)$ & \\
\hline $30 \%, 35 \%$ & $92(65)$ & $49(35)$ & \\
\hline $40 \%,>40 \%$ & $50(65)$ & $27(35)$ & \\
\hline$O D \times R S$ & & & $<0.001^{b}$ \\
\hline $0-11$ & $212(54)$ & $184(46)$ & \\
\hline $12-18$ & $308(40)$ & $462(60)$ & \\
\hline $19-25$ & $221(39)$ & $346(61)$ & \\
\hline $26-30$ & $100(53)$ & $89(47)$ & \\
\hline$>30$ & $171(67)$ & $86(33)$ & \\
\hline
\end{tabular}

Abbreviation: ODX RS, oncotype-DX recurrence score. Numbers in parentheses indicate percentages.

${ }^{\mathrm{a}} X^{2}$-test.

${ }^{b} x^{2}$-test for trends. 
a
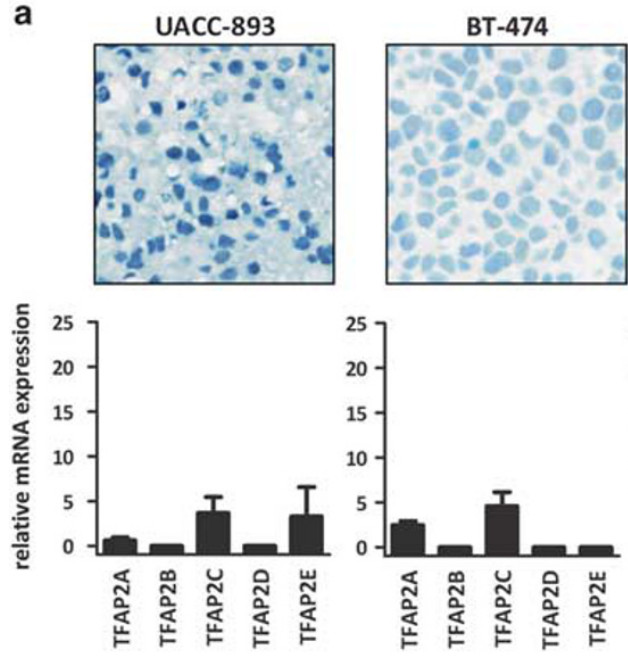

MDA-MB-361

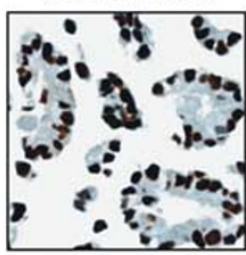

MDA-MB-134
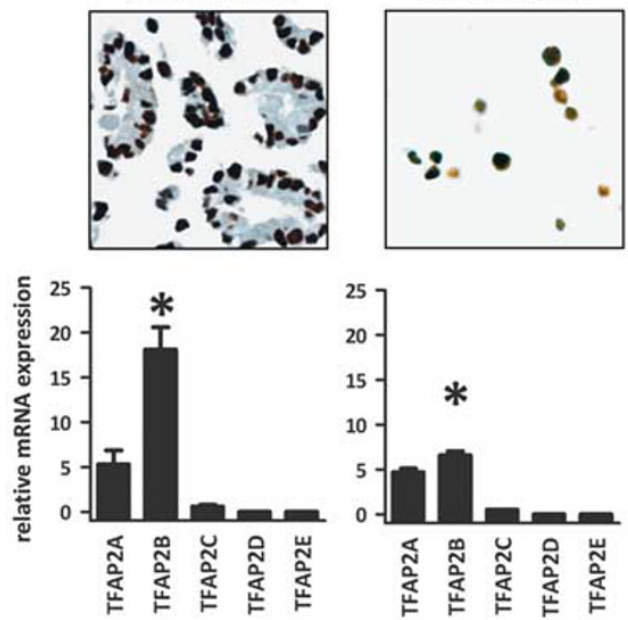
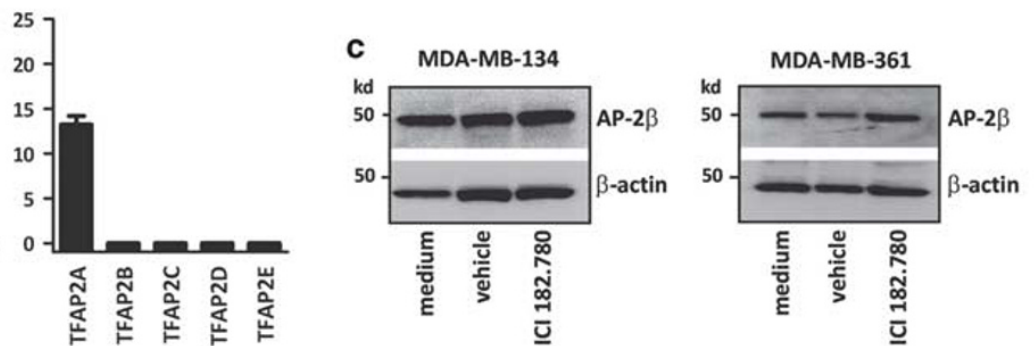

d
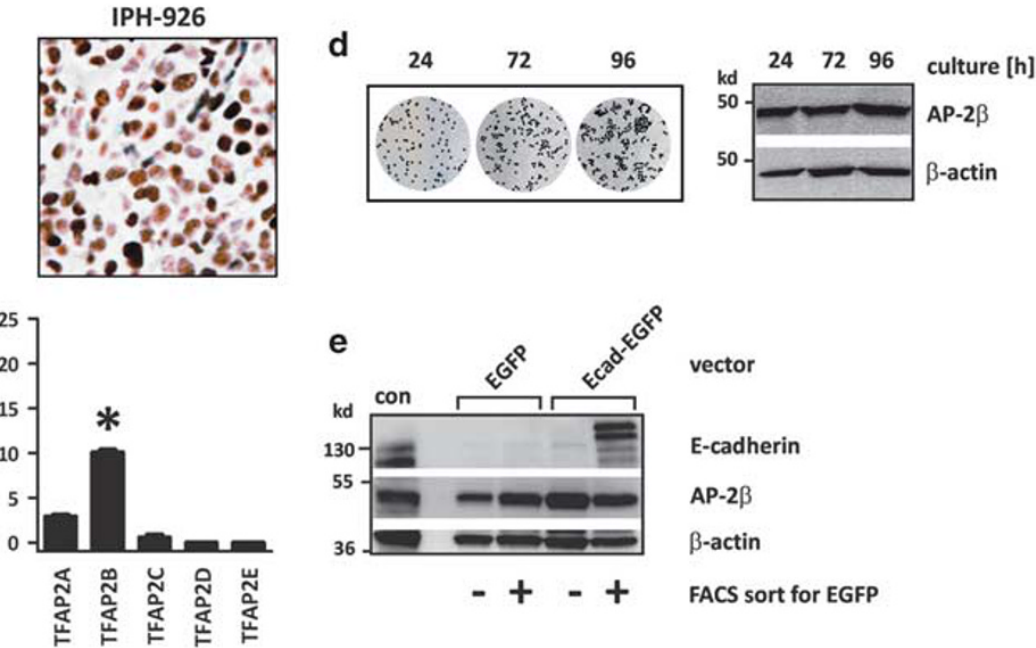

vector

E-cadherin

AP- $2 \beta$

$\beta$-actin

FACS sort for EGFP

Figure 6 TFAP2B/AP-2 $\beta$ expression in human BC cell lines. (a) Immunostaining of AP-2 $\beta$ using FFPE cell pellets and the H-87 antibody (top panels). Quantitative real-time RT-PCR (bottom panel). Data are presented as mean mRNA ratio relative to two housekeeping genes. Error bars represent SEM. TFAP2A, TFAP2C, TFAP2D, and TFAP2E were also included. Asterisks highlight enhanced TFAP2B mRNA expression. (b) Total cellular protein was separated by $12 \%$ SDS-PAGE and was probed with the anti-AP- $2 \beta$ antibody $\mathrm{H}-87$. Detection of $\beta$-actin verified equal loading. (c) AP- $2 \beta$ protein expression is independent from ER-signaling. Cells were exposed to the ER-antagonist ICI 182,780 (1 $\mu \mathrm{M})$ for $48 \mathrm{~h}$ and AP-2 $\beta$ protein expression was assessed by immunoblotting. Detection of $\beta$-actin verified equal loading. Appropriate cell stimulation was verified by flow cytometry as described previously. ${ }^{27}$ (d) AP- $2 \beta$ expression is independent from cell culture density. Cells were seeded in 6-well dishes at subconfluent density and were maintained for 24,72 or $96 \mathrm{~h}$ to obtain different cell culture densities (left panel). Then, AP-2 $\beta$ protein expression was assessed by immunoblotting (right panel). Shown are representative results from the MDA-MB-361 BC cell lines. (e) Reconstitution of E-cadherin fails to modulate AP- $2 \beta$ expression. E-cadherin-negative IPH-926 ILBC cells were transiently transfected with expression plasmids encoding EGFP-tagged full-length wild-type E-cadherin (Ecad-EGFP) or EGFP alone (EGFP). To compensate for limited transfection efficiency, positive cells were enriched by FACS sort as described previously. ${ }^{43}$ Total cellular protein was prepared $24 \mathrm{~h}$ after the transfection, was separated by $12 \%$ SDS-PAGE and was probed with the anti-AP- $2 \beta$ antibody H-87. Detection of $\beta$-actin verified equal loading.

TFAP2B among the genes upregulated in hyperplastic/ metaplastic mammary epithelium. ${ }^{49}$ It is likely, that the previously reported upregulation of TFAP $2 B$ mRNA in such lesions corresponds to an expansion of the AP- $2 \beta$-positive cell population, as described in the present work. A particularly intense and uniform staining for AP- $2 \beta$ was noted in LCIS. Cases of DCIS were more often AP- $2 \beta$-negative. Hence, $\mathrm{AP}-2 \beta$ is a mammary epithelial differentiation marker and various reactive mammary gland lesions and $\mathrm{BC}$ precursors, especially LCIS, are characterized by enhanced AP- $2 \beta$ expression.

In invasive $\mathrm{BC}, \mathrm{AP}-2 \beta$ expression was associated with ILBC. This is in line with few previously reported microarray gene expression data sets. ${ }^{22,24}$ AP- $2 \beta$ was also associated with a positive ER status, low proliferative activity, low/intermediate Oncotype-DX recurrence scores and other important clinicopathological characteristics. In a large clinical BC cohort (WSG PlanB trial) restricted to ER-positive/HER2-negative 
a
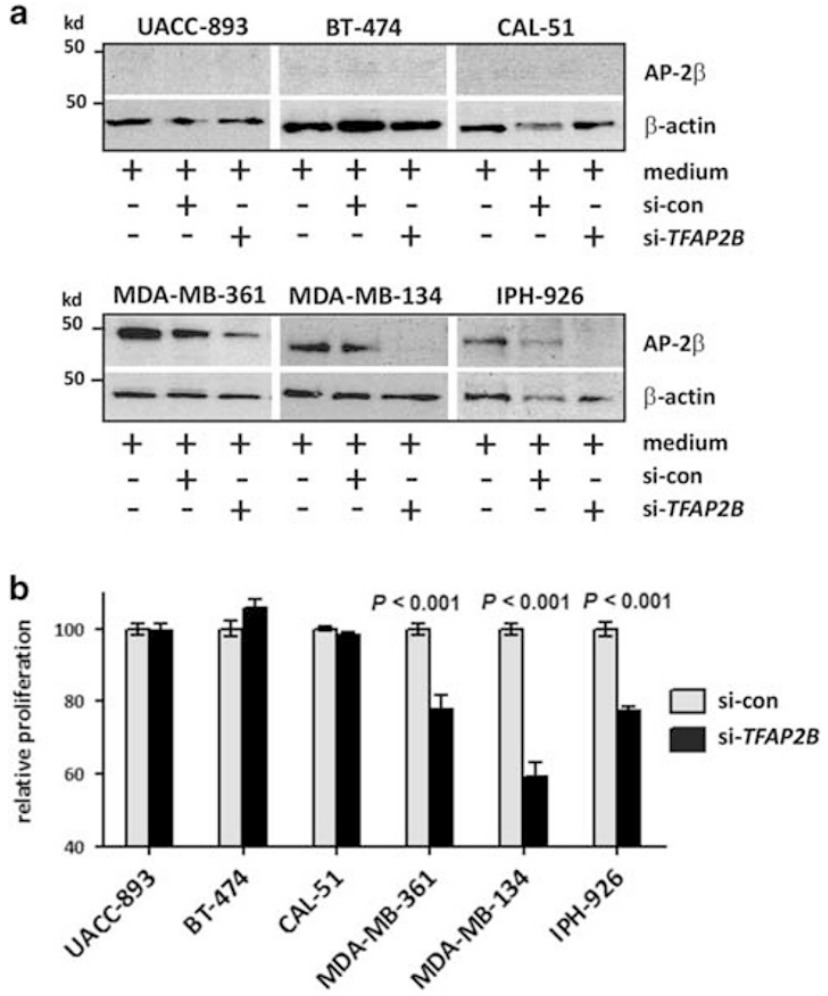

C

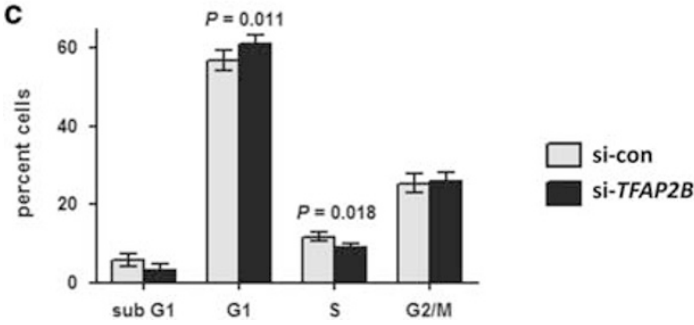

Figure 7 SiRNA-mediated inhibition of AP- $\beta$ diminishes proliferation of human $B C$ cell lines in vitro. (a) Cells were transiently transfected with siRNAs directed against TFAP2B (si-TFAP2B) or a mixture of non-targeting siRNAs (si-con) for $72 \mathrm{~h}$ and AP- $2 \beta$ protein expression was assessed by immunoblotting. Detection of $\beta$-actin verified equal loading. (b) Cells were transiently transfected si-TFAP2B or si-con for $72 \mathrm{~h}$. Subsequently, cells were cultured in fresh growth medium for $72 \mathrm{~h}$ and relative proliferation was determined with the WST-1 assay. Data are expressed as proliferation relative to control cells transfected with si-con. Error bars represent s.e.m. (c) Cells were transiently transfected si-TFAP2B or si-con for $72 \mathrm{~h}$ and were subjected to cell cycle analysis by flow cytometry. Shown are data obtained with the MDA-MB-134 cell line. Error bars represent s.e.m.

cases, AP- $2 \beta$ was still associated with ILBC. This highlights that the tight association of AP- $2 \beta$ with ILBC was not simply due to the high frequency of ER-positive cases or the common luminal molecular subtype in this special BC entity. Consistent with the overall favorable clinicopathological characteristics associated with AP- $2 \beta$, clinical follow-up data documented a prolonged event-free survival for AP- $2 \beta$ positive BC. Accordingly, AP- $2 \beta$ is not only a mammary epithelial differentiation marker, but has also prognostic implications in BC. However, additional analyses including 5year follow-up data and delimitation of different treatment modalities are warranted and underway to further explore the prognostic implications of AP- $2 \beta$ expression in BC. Furthermore, additional studies regarding the role of $\mathrm{AP}-2 \beta$ in HER2-positive BC, which were underrepresented in the present study focusing on ER-positive/HER2-negative BC, are warranted. Irrespective of these considerations, a very unusual relationship was observed between AP- $2 \beta$ expression and histological grade. AP- $2 \beta$-positivity rates declined with higher histological grade in IDBC, but not in ILBC. ILBCs retained AP- $2 \beta$ expression even in poorly differentiated (G3) cases. This further indicates a special role of AP- $2 \beta$ in ILBC.

Contrary to human BCs, mouse BCs from GEM models were all AP- $2 \beta$-negative. Lack of AP- $2 \beta$ expression in mouse $\mathrm{BC}$, including mouse lobular carcinomas, may have several reasons. This might reflect species-specific physiological differences just as the absence of ER and PR expression in conditional mouse BC models. ${ }^{38}$ Another possible explanation is that promoter elements driving Cre recombinase expression (MMTV, K14, WAP) target an AP-2 $\beta$-negative precursor cell. This however, is beyond the scope of the present work.

To study AP- $2 \beta$ on a functional level, we utilized human $\mathrm{BC}$ cell lines. TFAP2B/AP- $2 \beta$ mRNA and protein expression was detected in a subset of $\mathrm{BC}$ cell lines. All $\mathrm{AP}-2 \beta$-positive cell lines were derived from initially ER-positive carcinomas. Two of the AP- $2 \beta$-positive cell lines were derived from ILBC (MDA-MB-134 and IPH-926). These ILBC cell lines display moderate or slow in vitro growth characteristics. ${ }^{35,38}$ Accordingly, MDA-MB-134 and IPH-926 reflect the features of prototypic $\mathrm{AP}-2 \beta$-positive primary $\mathrm{BCs}$, as observed in our clinical tumor cohorts. This qualifies MDA-MB-134 and IPH-926 as appropriate models for studying AP- $2 \beta$ function in $\mathrm{BC}$, especially in the context of ILBC. Interestingly, IPH-926 corresponds to a G3-differentiated ILBC-relapse, which had undergone transition to a secondary ER-negative phenotype but it retained AP- $2 \beta$ expression. ${ }^{35,38,40}$ This suggests that ER-signaling is dispensable for AP- $2 \beta$ expression. Consistently, inhibition of ER-signaling by ICI 182,780 in MDA-MB-134 failed to suppress AP-2 $\beta$. This provides additional evidence that AP- $2 \beta$ expression is independent from ER-signaling in ILBC. Enhanced expression of AP- $2 \beta$ in apocrine metaplasia and the association of AP- $2 \beta$ with ARpositive BCs observed in the $\mathrm{MHH}$ cohort might suggest an AR-dependent expression of AP- $2 \beta$. However, a previously published profiling of AR-induced target genes in an appropriate $\mathrm{BC}$ cell model showed that TFAP2B expression is independent from AR-signaling. ${ }^{50}$ Moreover, AR-induced expression of AP- $2 \beta$ might not explain the AP- $2 \beta$-positive phenotype of IPH-926 lobular BC cells, since this cell line lacks AR expression. ${ }^{26}$

Alternatively, AP- $2 \beta$ expression might reflect a cellular origin from an AP- $2 \beta$-positive mammary epithelial precursor cell, but may have limited functional relevance for tumor 
growth. However, since siRNAs directed against TFAP2B induce apoptosis in aRMS cells, ${ }^{9}$ we evaluated the impact of $\mathrm{AP}-2 \beta$ inhibition in $\mathrm{BC}$ cell lines. SiRNAs directed against TFAP2B diminished in vitro growth of all $\mathrm{AP}-2 \beta$-positive $\mathrm{BC}$ cell lines tested. This growth-inhibitory effect was not associated with increased apoptotic cell death, but with an increased fraction of cells in the $\mathrm{G}_{0} / \mathrm{G}_{1}$-phase of the cell cycle. Therefore, AP- $2 \beta$ expression and function is at least partially different in aRMS and BC. In aRMS, AP- $2 \beta$ is aberrantly induced by $P A X 3-F O X O 1$ fusion proteins in a presumably AP-2 $\beta$-negative mesenchymal precursor cell and exerts critical anti-apoptotic signals in this cellular context. ${ }^{8,9,12}$ In $\mathrm{BC}, \mathrm{AP}-2 \beta$ expression seems to have its origin in an AP- $2 \beta-$ positive mammary epithelial precursor cell and it contributes to cell proliferation. In summary, $\mathrm{AP}-2 \beta$ is a mammary epithelial differentiation marker and its expression is preferentially retained in LCIS and lobular BC. Our findings indicate that AP- $2 \beta$ controls cell proliferation in this slowgrowing $\mathrm{BC}$ subtype.

Supplementary Information accompanies the paper on the Laboratory Investigation website (http://www.laboratoryinvestigation.org)

\section{ACKNOWLEDGMENTS}

This work was supported by the Claudia von Schilling breast cancer research junior award granted to MC.

\section{DISCLOSURE/CONFLICT OF INTEREST}

The authors declare no conflict of interest.

1. Pellikainen JM, Kosma VM. Activator protein-2 in carcinogenesis with a special reference to breast cancer-a mini review. Int J Cancer 2007;120: 2061-2067.

2. Moser M, Ruschoff J, Buettner R. Comparative analysis of AP-2 alpha and AP-2 beta gene expression during murine embryogenesis. Dev Dyn 1997;208:115-124.

3. Seki R, Kitajima K, Matsubara $H$, et al. AP-2beta is a transcriptional regulator for determination of digit length in tetrapods. Dev Biol 2015;407:75-89.

4. Martino VB, Sabljic T, Deschamps $P$, et al. Conditional deletion of AP-2beta in mouse cranial neural crest results in anterior segment dysgenesis and early-onset glaucoma. Dis Model Mech 2016;9: 849-861.

5. Hesse K, Vaupel K, Kurt S, et al. AP-2delta is a crucial transcriptional regulator of the posterior midbrain. PLoS One 2011;6:e23483.

6. Satoda M, Zhao F, Diaz GA, et al. Mutations in TFAP2B cause Char syndrome, a familial form of patent ductus arteriosus. Nat Genet 2000;25:42-46.

7. Lindgren CM, Heid IM, Randall JC, et al. Genome-wide association scan meta-analysis identifies three Loci influencing adiposity and fat distribution. PLoS Genet 2009;5:e1000508.

8. Wachtel M, Runge T, Leuschner I, et al. Subtype and prognostic classification of rhabdomyosarcoma by immunohistochemistry. J Clin Oncol 2006;24:816-822.

9. Ebauer M, Wachtel M, Niggli FK, et al. Comparative expression profiling identifies an in vivo target gene signature with TFAP2B as a mediator of the survival function of PAX3/FKHR. Oncogene 2007;26:7267-7281.

10. Ikram F, Ackermann S, Kahlert $\mathrm{Y}$, et al. Transcription factor activating protein 2 beta (TFAP2B) mediates noradrenergic neuronal differentiation in neuroblastoma. Mol Oncol 2016;10:344-359.

11. Li X, Glubrecht DD, Godbout R. AP2 transcription factor induces apoptosis in retinoblastoma cells. Genes Chromosomes Cancer 2010;49:819-830.
12. Grass B, Wachtel $M$, Behnke $S$, et al. Immunohistochemical detection of EGFR, fibrillin-2, P-cadherin and AP2beta as biomarkers for rhabdomyosarcoma diagnostics. Histopathology 2009;54:873-879.

13. Turner BC, Zhang J, Gumbs AA, et al. Expression of AP-2 transcription factors in human breast cancer correlates with the regulation of multiple growth factor signalling pathways. Cancer Res 1998;58: 5466-5472.

14. Pellikainen J, Kataja V, Ropponen K, et al. Reduced nuclear expression of transcription factor AP-2 associates with aggressive breast cancer. Clin Cancer Res 2002;8:3487-3495.

15. Orso F, Cottone E, Hasleton MD, et al. Activator protein-2gamma (AP-2gamma) expression is specifically induced by oestrogens through binding of the oestrogen receptor to a canonical element within the 5'-untranslated region. Biochem J 2004;377:429-438.

16. Friedrichs $\mathrm{N}$, Jager $\mathrm{R}$, Paggen $\mathrm{E}$, et al. Distinct spatial expression patterns of AP-2alpha and AP-2gamma in non-neoplastic human breast and breast cancer. Mod Pathol 2005;18:431-438.

17. Gee JM, Eloranta JJ, Ibbitt JC, et al. Overexpression of TFAP2C in invasive breast cancer correlates with a poorer response to antihormone therapy and reduced patient survival. J Pathol 2009;217: 32-41.

18. Williams CM, Scibetta AG, Friedrich JK, et al. AP-2gamma promotes proliferation in breast tumour cells by direct repression of the CDKN1A gene. EMBO J 2009;28:3591-3601.

19. Shiu KK, Wetterskog D, Mackay A, et al. Integrative molecular and functional profiling of ERBB2-amplified breast cancers identifies new genetic dependencies. Oncogene 2013;33:619-631.

20. Perou CM, Sorlie T, Eisen MB, et al. Molecular portraits of human breast tumours. Nature 2000;406:747-752.

21. Hu Z, Fan C, Oh DS, et al. The molecular portraits of breast tumors are conserved across microarray platforms. BMC Genomics 2006;7:96.

22. Weigelt B, Geyer FC, Natrajan R, et al. The molecular underpinning of lobular histological growth pattern: a genome-wide transcriptomic analysis of invasive lobular carcinomas and grade- and molecular subtype-matched invasive ductal carcinomas of no special type. J Pathol 2010;220:45-57.

23. Guedj $M$, Marisa $L$, de Reynies $A$, et al. A refined molecular taxonomy of breast cancer. Oncogene 2012;31:1196-1206.

24. Korkola JE, DeVries S, Fridlyand J, et al. Differentiation of lobular versus ductal breast carcinomas by expression microarray analysis. Cancer Res 2003;63:7167-7175.

25. Otto $B$, Streichert $T$, Wegwitz $F$, et al. Transcription factors link mouse WAP-T mammary tumors with human breast cancer. Int J Cancer 2013;132:1311-1322

26. Christgen M, Geffers $\mathrm{R}$, Kreipe $\mathrm{H}$, et al. IPH-926 lobular breast cancer cells are triple-negative but their microarray profile uncovers a luminal subtype. Cancer Sci 2013;104:1726-1730.

27. Christgen $M$, Bruchhardt $H$, Ballmaier $M$, et al. KAI1/CD82 is a novel target of estrogen receptor-mediated gene repression and downregulated in primary human breast cancer. Int J Cancer 2008;123: 2239-2246.

28. Gluz O, Nitz UA, Christgen M, et al. West German Study Group Phase III PlanB Trial: First Prospective Outcome Data for the 21-Gene Recurrence Score Assay and concordance of prognostic markers by central and local pathology assessment. J Clin Oncol 2016;34:2341-2349.

29. Schulze-Garg C, Lohler J, Gocht A, et al. A transgenic mouse model for the ductal carcinoma in situ (DCIS) of the mammary gland. Oncogene 2000;19:1028-1037.

30. Meyer DS, Brinkhaus $\mathrm{H}$, Muller $\mathrm{U}$, et al. Luminal expression of PIK3CA mutant H1047R in the mammary gland induces heterogeneous tumors. Cancer Res 2011;71:4344-4351.

31. Derksen PW, Braumuller TM, van der Burg E, et al. Mammary-specific inactivation of E-cadherin and p53 impairs functional gland development and leads to pleomorphic invasive lobular carcinoma in mice. Dis Model Mech 2011;4:347-358.

32. Boelens MC, Nethe M, Klarenbeek S, et al. PTEN loss in E-Cadherindeficient mouse mammary epithelial cells rescues apoptosis and results in development of classical invasive lobular carcinoma. Cell Rep 2016;16:2087-2101.

33. Mengel $M$, von Wasielewski $\mathrm{R}$, Wiese $\mathrm{B}$, et al. Inter-laboratory and interobserver reproducibility of immunohistochemical assessment of the Ki-67 labelling index in a large multi-centre trial. J Pathol 2002;198: 292-299. 
34. Remmele W, Stegner HE. [Recommendation for uniform definition of an immunoreactive score (IRS) for immunohistochemical estrogen receptor detection (ER-ICA) in breast cancer tissue]. Pathologe 1987;8: 138-140.

35. Christgen $M$, Bruchhardt $H$, Hadamitzky $C$, et al. Comprehensive genetic and functional characterization of IPH-926: a novel CDH1-null tumour cell line from human lobular breast cancer. J Pathol 2009;217: 620-632.

36. Christgen M, Geffers R, Ballmaier $M$, et al. Down-regulation of the fetal stem cell factor SOX17 by H33342: a mechanism responsible for differential gene expression in breast cancer side population cells. J Biol Chem 2010;285:6412-6418.

37. Krech T, Scheuerer E, Geffers R, et al. ABCB1/MDR1 contributes to the anticancer drug-resistant phenotype of $\mathrm{IPH}-926$ human lobular breast cancer cells. Cancer Lett 2012;315:153-160.

38. Christgen M, Derksen P. Lobular breast cancer: molecular basis, mouse and cellular models. Breast Cancer Res 2015;17:16.

39. Dirks WG, Faehnrich $S$, Estella IA, et al. Short tandem repeat DNA typing provides an international reference standard for authentication of human cell lines. Altex 2005;22:103-109.

40. Christgen M, Noskowicz M, Heil C, et al. IPH-926 lobular breast cance cells harbor a p53 mutant with temperature-sensitive functional activity and allow for profiling of p53-responsive genes. Lab Invest 2012;92:1635-1647.

41. Uphoff CC, Drexler HG. Detection of mycoplasma contaminations. Methods Mol Biol 2005;290:13-23.

42. Fuchs $M$, Hutzler $P$, Handschuh $G$, et al. Dynamics of cell adhesion and motility in living cells is altered by a single amino acid change in
E-cadherin fused to enhanced green fluorescent protein. Cell Motil Cytoskelet 2004;59:50-61.

43. Karch I, Schipper E, Christgen $\mathrm{H}$, et al. Is upregulation of BCL2 a determinant of tumor development driven by inactivation of CDH1/Ecadherin? PLoS One 2013;8:e73062.

44. Christgen $M$, Ballmaier $M$, Bruchhardt $H$, et al. Identification of a distinct side population of cancer cells in the Cal-51 human breast carcinoma cell line. Mol Cell Biochem 2007;306:201-212.

45. Christgen M, Steinemann D, Kuhnle $E$, et al. Lobular breast cancer: clinical, molecular and morphological characteristics. Pathol Res Pract 2016;212:583-597.

46. Christgen M, Bartels S, van Luttikhuizen JL, et al. Subclonal analysis in a lobular breast cancer with classical and solid growth pattern mimicking a solid-papillary carcinoma. J Pathol Clin Res 2017;3:191-202.

47. Gluz O, Nitz U, Christgen M, et al. The WSG Phase III PlanB Trial: first prospective outcome data for the 21-gene recurrence score assay and concordance of prognostic markers by central and local pathology assessment. J Clin Oncol 2016;34:2341-2349.

48. Frasor J, Stossi F, Danes JM, et al. Selective estrogen receptor modulators: discrimination of agonistic versus antagonistic activities by gene expression profiling in breast cancer cells. Cancer Res 2004;64: $1522-1533$.

49. Lee S, Medina D, Tsimelzon A, et al. Alterations of gene expression in the development of early hyperplastic precursors of breast cancer. Am J Pathol 2007;171:252-262.

50. Robinson JL, Macarthur S, Ross-Innes CS, et al. Androgen receptor driven transcription in molecular apocrine breast cancer is mediated by FoxA1. EMBO J 2011;30:3019-3027. 